\title{
Ruptured Conus Medullaris Dermoid Cyst with Fat Droplets in the Central Canal
}

\author{
Mayur Sharma, Rahul Mally, Vernon Velho
}

Department of Neurosurgery, Sir J. J. Group of Hospitals, Grant Medical College, Mumbai, India

Asian Spine Journal 2013;7(1):50-54

http://dx.doi.org/10.4184/asj.2013.7.1.50

This article on Asian Spine Journal was initially published without the word 'Canal' in the title.

The title should be corrected as the following:

from "Ruptured Conus Medullaris Dermoid Cyst with Fat Droplets in the Central"

to "Ruptured Conus Medullaris Dermoid Cyst with Fat Droplets in the Central Canal" 